
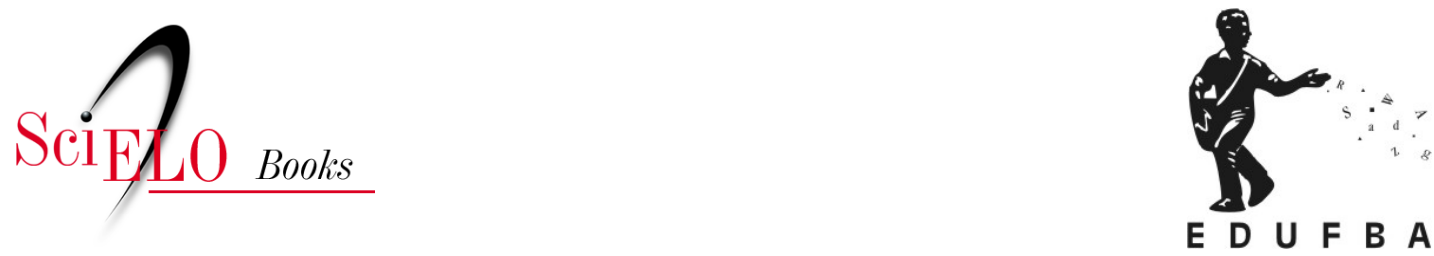

\title{
(Re)organizar a solidariedade
}

\author{
Genauto Carvalho de França Filho \\ Philippe Eynaud
}

\section{SciELO Books / SciELO Livros / SciELO Libros}

FRANÇA FILHO, G. C., and EYNAUD, P. (Re)organizar a solidariedade. In.: Solidariedade e organizações: pensar uma outra organização [online]. Salvador: EDUFBA; Ateliê de Humanidades, 2020, pp. 71-103. ISBN: 978-65-5630-199-0. https://doi.org/10.7476/9786556301990.0003.

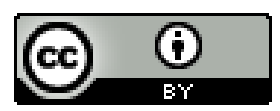

All the contents of this work, except where otherwise noted, is licensed under a Creative Commons Attribution 4.0 International license.

Todo o conteúdo deste trabalho, exceto quando houver ressalva, é publicado sob a licença Creative Commons Atribição 4.0.

Todo el contenido de esta obra, excepto donde se indique lo contrario, está bajo licencia de la licencia Creative Commons Reconocimento 4.0. 


\section{(Re)organizar a solidariedade}

Vimos no capítulo anterior que um enorme inconsciente marcou a história da relação entre solidariedade e organização, impedindo a possiblidade da plena realização desse vínculo, mas que, ao mesmo tempo, outras trajetórias de pensamento teriam sido possíveis. Essas poderiam ter aberto uma relação de muita proximidade entre os dois conceitos. De fato, parece que a visão clássica e ortodoxa de uma economia de mercado centrada na questão do empreendedorismo mercantil influenciou fortemente a formação conceitual da teoria das organizações. As pressuposições do individualismo metodológico desenvolvido nessa teoria têm, de fato, frustrado a possibilidade de um pensamento em termos de solidariedade dentro desse campo. Neste segundo capítulo, nos propomos ir além dessa constatação simples, questionando as condições de aproximação entre a questão organizacional e a preocupação solidária. Primeiro, discutiremos a questão econômica como um pré-requisito para essa reavaliação. Veremos como o arcabouço conceitual de Polanyi fornece os elementos necessários para repensar as teorias da organização. Isso nos levará a deduzir, com Guerreiro Ramos, os fundamentos conceituais de uma nova teoria das organizações permitindo combinar plenamente os dois termos: "organização" e "solidariedade".

\section{ORGANIZAR A SOLIDARIEDADE REPENSANDO SUA ECONOMIA}

A estrutura do pensamento econômico dominante coloca os mecanismos de mercado no centro de sua análise, invalidando, portanto, qualquer abordagem que busque descrever e compreender plenamente as relações de 
solidariedade. Antes mesmo de tentarmos organizar a solidariedade, precisamos sair dessa invalidação escolhendo uma estrutura mais ampla de análise. A proposta conceitual de Polanyi é, nesse sentido, pertinente. Ao combinar história, antropologia, sociologia e economia, Polanyi desenvolve uma abordagem transdisciplinar original e faz várias contribuições particularmente importantes sobre a nossa questão inicial. Em primeiro lugar, amplia o campo de observação da economia no tempo e no espaço para definir seu conceito de economia substantiva. Isso leva-o a revelar a construção ideológica que acompanhou e favoreceu o crescimento dos mercados autorregulados. Finalmente, ele deduz orientações em termos da análise das forças em jogo e da questão, central para ele, do desenraizamento.

\section{A economia não se reduz ao mercado}

Polanyi mostra, antes de tudo, que o mercado não é a forma exclusiva de circulação de bens e serviços econômicos. O autor qualifica de sofisma economicista a vontade, doravante comum, de reduzir a economia a uma economia de mercado. Para ele, a importância adquirida pelo mercado em nossas sociedades tende, com efeito, a mascarar outras formas de economia que coexistem com o mercado, como a reciprocidade, a redistribuição ou a domesticidade - que serão esclarecidas mais adiante. A análise histórica proposta por Polanyi é particularmente esclarecedora sobre esse assunto. Ele salienta que a dominação do mercado é historicamente datada e relativamente recente, sendo o período atual um caso de exceção, do ponto de vista do conjunto da história da humanidade. Apoiando-se em inúmeros trabalhos de autores clássicos da antropologia como Bronislaw Malinovski, Franz Boas, Richard Turnwald e Marcel Mauss, Polanyi demonstra que outros princípios econômicos, como a reciprocidade - relativamente invisibilizada hoje - e a redistribuição, primaram no passado. Podemos assim pensar que Mauss está na linha de Leroux. "Leroux e Mauss concordam em pensar, um sob o nome de solidariedade, o outro sob o nome de dádiva, que dar e receber, longe de se opor, são gestos complementares que juntos constituem a única alternativa 
à violência e a própria definição da vida, desde o nível biológico até o nível social". (VIARD; VAILLANCOURT, 2000, p. 24)

Na época pré-moderna, a fixação dos preços das trocas nos mercados era decisão das autoridades e dos responsáveis pela cidade. O funcionamento dos mercados estava enraizado nos mecanismos de controle sociais e políticos. Polanyi mostra que a ascensão forte do capitalismo está associada à emergência dos mercados autorregulados; isto é, mercados caracterizados pela fixação de preços não controlados. Num mercado autorregulado, os preços são gerados pela lei de oferta e demanda e não dependem - em primeira análise - de fatores sociais, culturais ou políticos. O autor avança na ideia de que a aparição dos mercados autorregulados foi o fator desencadeador da "grande transformação" observada nas sociedades com o advento do período moderno. (POLANYI, I986) Sem a multiplicação desse tipo de mercado, a economia de mercado não teria podido se impor, nem a percepção dos atores teria se modificado. O crescimento da economia de mercado está, portanto, ligado ao desenraizamento progressivo do econômico vis-à-vis das relações sociais. O avanço em força do mercado que naturalizamos hoje é, portanto, em grande parte, uma construção ideológica. O desenraizamento social e político do mercado o valorizou, conferindo-o uma nova legitimidade. O capitalismo aproveitou esta mutação para inverter a relação de dependência: doravante é a sociedade que se encontra enraizada no mercado. Evidentemente que essa abordagem pode ser ligeiramente relativizada, pois as lógicas de mercado não se resumem sempre à simples busca do interesse material. Elas estão também submetidas pontualmente aos desafios de reconhecimento, de poder ou de socialização. (GRONOVETTER, 200o) Granovetter afirma que Polanyi de alguma forma ofereceu uma versão "super-socializada" das economias não modernas e "sub-socializadas" da economia de mercado. (MAUCOURANT, 2005, p. II3) Em todo caso, prevalece a constatação histórica da grande transformação, cuja principal característica tem sido a hegemonia da lógica de mercado sobre o conjunto das sociedades modernas. 


\section{A proposta de uma economia substantiva}

Com base na constatação histórica relativa à excepcionalidade do sofisma economicista, Polanyi avança o conceito de economia substantiva. Para ele, a economia encontra historicamente sua origem na dependência do homem em relação à natureza e aos seus semelhantes. Ele deduz, então, a necessidade para os homens de gerir essa dependência como forma de garantir sua sobrevivência. O significado substantivo, portanto, vem da "dependência manifesta do homem em relação à natureza e à seus semelhantes para obter sua subsistência". (POLANYI, 2OII, p. 56) Polanyi distingue dois níveis no seio da economia substantiva: a interação dos homens com o meio ambiente e a institucionalização que dela decorre. Esta última tem por objetivo tirar os homens de sua precariedade, não repousando sua sobrevivência numa cadeia de causalidade frágil. (POLANYI, 2OII) É esse processo de institucionalização que interessa a Polanyi e que é a força da sua proposta. A característica do pensamento de Polanyi é, de fato, procurar estar no âmago da tensão entre ator e instituição e de "manter essa exigência intelectual ao longo de suas análises históricas, sem recair de um lado (individualismo metodológico) ou do outro (holismo ou estruturalismo)". (POSTEL; SOBEL, 2OIO, p. 3I)

A partir de então, Polanyi contrapõe a economia substantiva ao que ele chama de economia formal. Esta última negligencia a dimensão institucional, concentrando-se apenas no processo único de economia dos meios em um contexto de escassez. Para criticar essa opção mantida pela economia formal, Polanyi refere-se a Menger (1923). Ele sublinha neste economista duas perspectivas econômicas mencionadas na última versão de seus "princípios": uma defendendo uma abordagem em termos de falta de recursos e escassez, a outra enfatizando "as demandas físicas de produção independentemente da abundância ou insuficiência dos meios".' (POLANYI, 1986) A partir dessa segunda concepção, Polanyi constrói sua proposta de economia substantiva. Para ele, é uma questão de prestar atenção "à indústria em vez dos negócios,

\footnotetext{
1 Citado por Maucourant (2005, p. 71).
} 
à tecnologia em vez do cerimonialismo, aos meios de produção em vez dos títulos de propriedade, ao capital produtivo em vez das finanças, aos bens de capital em vez do capital, em uma palavra, a substância da economia e não à sua forma e terminologia de mercado". (POLANYI, 20II, p. 38) Ao fazê-lo, a economia substantiva não se constrói em torno da escassez. Como disse Berthoud (citado em POLANYI, I986, p. 72): "o significado substantivo não implica nem escolha, nem insuficiência. A subsistência do homem pode ou não suscitar a necessidade de escolher. O costume e a tradição, em geral, eliminam a escolha e, se ela existir, não precisa ser causada pelos efeitos limitantes de qualquer escassez de meios".

Polanyi libera, assim, a decisão econômica da referência apenas à escassez. Ele ressalta que a dificuldade de fazer uma escolha pode "advir tanto da abundância quanto da insuficiência de meios" (POLANYI, 20II, p. 63) O desejo de Polanyi é construir uma visão mais ampla da economia que abraça a história das economias modernas e não modernas. Como estas últimas não eram dominadas pelo mercado, a situação de escassez não era a regra. Polanyi vai buscar em Aristóteles os argumentos para sua proposição. Ele nota que Aristóteles pensa que "a verdadeira riqueza de uma casa, ou de um Estado, são os bens necessários para a vida que podem ser armazenados e que podem ser conservados. Estes não são apenas meios para um fim; como todos os meios, eles são naturalmente limitados e determinados por seus fins. Na casa, eles são os meios de existência; no Estado, estes são os meios da boa vida. Os desejos e as necessidades humanas não são, portanto, ilimitados". (POLANYI, 20II, p.70) A economia substantiva é então considerada em referência a uma cidade antiga que defende o princípio de uma boa vida e, assim, limita o espaço concedido às relações de mercado.

Polanyi, portanto, se opõe aos fundamentos da economia de mercado: as necessidades não são ilimitadas e as escolhas não se limitam a questões de escassez. Polanyi, igualmente, critica o conceito de propriedade, central na economia de mercado, ao relativizá-la. Ele se refere a Mead para lembrar que nas sociedades antigas é o homem que "pertence à parcela de terra, não à terra 
que pertence ao homem". (POLANYI, 2OII, p. 97) Polanyi também observa que, na lógica mercantil, a gama de necessidades humanas é bastante reduzida, mantendo apenas aquelas cuja tradução é possível em "escalas de valor utilitárias de indivíduos isolados operando em mercados". (POLANYI, 2OII, p. 48)

\section{A questão das mercadorias fictícias}

Entender como os mercados se transformam em mercados autorregulados e passam a ocupar a grande centralidade nas sociedades modernas constitui um dos objetivos maiores da obra de Polanyi (20II). Outro interesse do trabalho do autor é destacar as condições da ascensão do mercado. No longo período histórico em que predominava a reciprocidade e a redistribuição, "o comércio, a moeda e os mercados não constituíam um conjunto institucional integrado". (POLANYI, 20II, p. 367) Os mercados existiam, mas eram socialmente regulados. A fixação dos preços nesses mercados implicava diretamente os próprios atores concernidos, diferentemente do que ocorrerá com a aparição dos mercados autorregulados.

Para explicar como uma mudança tão profunda foi possível, Polanyi (I986, 20II) avança a hipótese de uma vontade deliberada de transformação de três fatores de produção - o trabalho, a moeda e a natureza - em mercadorias. Esses três fatores não foram escolhidos ao acaso. Com efeito, eles tentam responder a uma possível limitação no exercício de um mercado autorregulado: o mercado tendo a necessidade de atribuir um preço às matérias-primas, um preço ao número de horas trabalhadas e um preço aos bens de produção financiados pelo crédito. A pressão é importante, pois a "construção política destes três mercados é a condição sine qua non da aparição de um mercado autorregulador". (POSTEL; SOBEL, 2OIO, p. 9)

Para Polanyi (1986), essa transformação é, a priori, inconcebível. O trabalho, a moeda e a natureza não são mercadorias. Jamais esses fatores foram produzidos para serem vendidos. Existe assim, segundo o autor, um trabalho ideológico contribuindo para criar e entreter uma ficção avaliada por ele como a mais potente ficção já imaginada. "Mercadorizar" tais fatores apre- 
senta, então, uma dupla vantagem: a alimentação ilimitada dos mercados graças a uma regulação automática dos fluxos e o enfraquecimento das resistências sociais, diante de um dispositivo anônimo. A economia de mercado tem, portanto, necessidade dessas "mercadorias fictícias" para assentar sua hegemonia e assegurar sua extensão sem fim.

O processo de mercadorização do trabalho, da moeda e da natureza não foi realizado de maneira linear. Constata-se que as ondas de mercadorização se sucedem e se entrecruzam "na medida em que elas passam do trabalho à moeda e em seguida à natureza, cada onda integrando a mercadorização do período precedente" para minar, com uma força cada vez maior, "os direitos do trabalho, em seguida os direitos sociais (que compreendem os direitos do trabalho) e os direitos humanos que englobam estes três tipos de direitos". (BURAWOY, 2OI3, p. IO3) Desde então, a constatação é clara: o desenvolvimento do mercado se joga em desfavor da democracia. A partir de questões tão importantes quanto o bem-estar e a realização no trabalho, a confiança na moeda ou a preservação da natureza, a economia de mercado instala seus próprios dispositivos para invalidar qualquer controle social. O recurso à história é muito pertinente neste caso, pois nos mostra que este fenômeno de desenraizamento não é inelutável - ele foi notadamente revertido depois da Segunda Guerra Mundial com a Declaração de Filadélfia ${ }^{2}$ e a vitória contra o

2 Este é o título de um documento aprovado na $26^{\text {a }}$ Conferência da Organização Internacional do Trabalho (OIT), ocorrida logo ao final da segunda grande guerra, em 10 de maio de 1944, na cidade de Filadélfa, nos Estados Unidos, e que foi anexada à constituição da OIT em 1946. Essa Declaração afirmou uma série de princípios e estabeleceu um pacto de entendimento entre as nações segundo o qual não seria possível construir o desenvolvimento econômico sem o desenvolvimento social, isto é, um conjunto de direitos sociais mais amplos - habitação, saúde, educação, entre outros - garantidores das condições de bem-estar de vida para as famílias num mundo que se pretendia civilizado. Os princípios e preconizações da Declaração de Filadélfa inspiraram e orientaram as grandes políticas de desenvolvimento do pós-guerra nos Estados Unidos e os principais países da Europa, servindo de base aos "trinta gloriosos", expressão difundida por economistas e outros estudiosos para explicar a grande expansão e êxito no desenvolvimento das principais economias do ocidente, cuja característica marcante foi o elevado padrão de distribuição da riqueza e generalização do bem-estar social na população. A principal contra reação às preconizações da Declaração da Filadélfa veio quase meio século depois, em 1989, através de um outro documento que ficou conhecido como Consenso de Washington. Este foi formulado por economicistas de instituições financeiras situadas em Washington D.C., como o Fundo Monetário 
fascismo. (SUPIOT, 20I0) A reversibilidade hoje pode se exprimir sob a forma de novos arranjos e dispositivos institucionais socioeconômicos inovadores conforme abordaremos no capítulo seguinte.

\section{As implicações da economia substantiva para a teoria das organizações}

A grade analítica Polanyiana traz muitos desafios fortes para a orientação da teoria das organizações. Vamos agora tentar fazer um inventário dos principais. Em primeiro lugar, a abordagem de Polanyi enfatiza a importância de um estudo de longo prazo dos fenômenos e da força que a abordagem histórica pode ter ao sair dos prismas que bloqueiam o pensamento. Isso confirma um elemento que já enfatizamos no capítulo anterior, referindo-se aos trabalhos de historiadores da administração. Esse esquecimento da história é, sem dúvida, mais agudo para as ciências relativamente jovens, como a teoria das organizações que podem ser tentadas a negligenciar sua contribuição. Além disso, Polanyi é muito crítico de uma visão evolucionista e finalista da história econômica. Com Benjamin (2017), ele considera a história separada de uma narrativa linear e dentro de uma série imprevisível de continuidades e descontinuidades.

O segundo ponto de importância trazido pelo conceito de economia substantiva é a autonomização da esfera econômica e sua assimilação ao mercado. A grande transformação da qual Polanyi se refere é primeiramente aquela da separação entre política e economia. (POLANYI, I983) Essa separação, concomitante ao nascimento das ciências da organização, não foi

\footnotetext{
Internacional (FMI), o Banco Mundial e o Departamento do Tesouro dos Estados Unidos. Nessa ocasião, decide-se que as garantias sociais teriam um custo elevado para os estados, devendo o desenvolvimento ser perseguido apenas através das livres forças de mercado, reatualizando então a ênfase exclusiva na ideia de crescimento. O documento se tornou a política oficial do FMI em 1990, quando passou a ser "receitado" para promover o ajuste macroeconômico dos países em desenvolvimento que passavam por dificuldades. Tais políticas ficaram também conhecidas como "neoliberais" pelo seu conteúdo revisionista das principais teses do liberalismo econômico. Posteriormente, sucessivas crises nos países que apostaram neste modelo fizeram o FMI rever suas posições.
} 
neutra. Ela teve o efeito de limitar a reflexão organizacional ao contexto das empresas de mercado e de limitar a exploração dos pontos de interação entre política e economia. Para Polanyi, a reabilitação do poder do cidadão passa por "uma economia democraticamente controlada e socialmente enraizada". (BIRCHFIELD, 20I4) Esse enraizamento é de fato suscetível de devolver ao cidadão seu poder de decisão sobre a vida econômica, ao passo em que reabilita a política. Essa opção tem o efeito de reposicionar a análise organizacional. Com uma análise substantiva, a sociedade e a política não estão fora do escopo. Elas participam legitimamente no estudo organizacional. Trata-se, para os teóricos da organização, de exercitar o descentramento, e não mais considerar a empresa comercial como a única unidade de medida para suas observações e a única referência para seus estudos e recomendações. A estrutura conceitual substantivista chama atenção para se olhar outros territórios de análise.

A terceira contribuição da grade analítica polanyiana é de autorizar uma melhor leitura para dar conta do surgimento e do aumento de importância das organizações do campo da Economia Social e Solidária (ESS). Esse campo identifica alguns atores históricos como as cooperativas, as associações e as organizações mutualistas, às quais hoje vêm juntar-se uma variedade de novas formas de organizações em campos os mais diversos como as finanças solidárias, o comércio justo, a produção agroecológica, dentre inúmeros outros. O reconhecimento dessas diferentes formas de organizações constitui uma realidade hoje em inúmeros países, com a aparição e novos marcos legais para a Economia Social e Solidária.

No Brasil, a economia solidária teve grande impulso, especialmente no período entre 2003 e 2016, durante a vigência da Secretaria Nacional de Economia Solidária (Senaes), então ligada ao Ministério do Trabalho. Nessa ocasião, o fortalecimento da economia solidária como campo institucional foi importante em pelo menos quatro âmbitos: na multiplicação e diversificação das iniciativas, quando se iniciava o estabelecimento de um quadro legal para a regulamentação das suas formas de organização através da nomenclatura "empreendimentos econômicos solidários"; no fortalecimento da atuação de Entidades 
de Apoio e Fomento (EAF), como incubadoras universitárias e organizações da sociedade civil; na constituição e expansão dos fóruns e redes de economia solidária nos diferentes cantos do território nacional; e, na diversificação das políticas públicas neste campo nos três níveis da esfera governamental. (FRANÇA FILHO et all, 2006) As práticas, reflexões e estudos sobre o tema indicavam a necessidade de se repensar a organização econômica da sociedade num caminho de valorização de práticas de democracia econômica.

Na França, a ESS foi formalmente reconhecida em dezembro de 2014 através do seu marco legal maior (loi-cadre). Esta lei estabelece no seu primeiro artigo que as organizações de ESS se reconhecem na busca de um objetivo que não esteja limitado à repartição de benefícios e implementem governabilidade democrática. Aqui, podemos ver se desenhar claramente o enraizamento que Polanyi se refere e a possibilidade de uma democratização da economia.

A quarta contribuição é uma reflexão diferente sobre o espaço das trocas entre os atores econômicos. No caso de uma troca de mercado, o acordo é fixado no momento da assinatura de um contrato que supõe garantir o equilíbrio da transação - através de um mecanismo de ajuste de preço - e sua conclusão - pelo pagamento resultante. Tudo é jogado então no tempo presente entre dois atores quaisquer que se sabe apenas que eles se encontram em um mercado. A explicitação de outras lógicas econômicas feitas por Polanyi, como a reciprocidade e a redistribuição, contribui para o enriquecimento da grade de leitura das interações entre os atores. Elas tornam possível sair da referência à contratualidade, que se tornou uma forma social geral "no mundo dos negócios, comercial ou privado, tanto quanto nas esferas social e política”. (CAILLÉ, 2005, p. I43). Assim, a reciprocidade se liberta do contrato. Não está vinculada a uma necessidade de equivalência ou de uma iniciativa formal. A reciprocidade descreve o "movimento de bens e serviços (ou sua eliminação) entre os pontos de um arranjo simétrico". (POLANYI, 2OII, p. 78) A redistribuição, por sua vez, significa um "movimento em direção a um centro e, depois, do centro para o exterior, quer os objetos sejam deslocados fisicamente, quer sua disposição seja sim- 
plesmente modificada". (POLANYI, 2OII, p. 78) O centro pode ser o chefe da aldeia ou o Estado social. Ao contrário da troca mercantil, ela não é resolvida por um contrato entre duas partes. Podemos, portanto, fazer uma leitura espacial do trabalho de Polanyi, no qual as formas de integração podem ser representadas por "diagramas que ilustram os tipos de movimentos de bens e pessoas: mudanças de localização, de apropriação, ou às vezes ambos". (POLANYI, 2OII, p. 78) Se dobrarmos essa leitura espacial com uma leitura temporal, a lógica da reciprocidade e da redistribuição aparecerão mais ricas. As figuras espaciais são mais complexas e a lógica do tempo longo prevalece. Ao contrário da lógica de mercado, elas têm grande poder de socialização.

A quinta contribuição de Polanyi está relacionada com a decisão de gestão. Se a referência das teorias organizacionais deixa de ser uma economia baseada na escassez, mas uma economia substantiva, a questão da decisão é profundamente transformada. A primeira consequência é que a decisão não se traduz necessariamente em um cálculo de otimização. Pode ser que a escolha deva ser feita entre opções ou soluções equivalentes. Também é possível que a escolha seja expressa em face dos meios suficientes (ou não). O abandono do princípio da escassez abre um campo de possibilidades. A escolha pode ser livremente baseada em outros critérios: morais e éticos. A escolha perde seu caráter técnico e inadequado para se tornar um critério político novamente. A escolha pode ser compartilhada, pode ser objeto de uma discussão, enfim, ser uma escolha coletiva.

A sexta contribuição para o entendimento das organizações em Polanyi diz respeito à questão das mercadorias fictícias. Denunciar a ficção mercantil em torno do trabalho, do dinheiro e da natureza supõe uma consciência dentro das organizações que se relaciona a um princípio de precaução. Como engajar a gestão na desmercadorização de mercadorias fictícias? Três perspectivas se abrem. A primeira se situa na valorização do trabalho face ao capital. Essa se expressa através de mecanismos de proteção dos interesses dos trabalhadores, na capacidade de participação nas decisões, nas limitações de dife- 
renças na renda, na regulação do poder dos provedores de capitais. Em todos esses aspectos, a experiência adquirida entre os atores históricos da economia social é rica e relevante. A segunda é a questão da moeda. Polanyi mostra que as sociedades antigas possuíam várias moedas para vários usos. A aparição de moedas locais é parte dessa renovação sobre questões da apropriação social da moeda fora da unidade monetária nacional. Por fim, a questão da natureza refere-se às externalidades ambientais negativas das empresas e refere-se a métodos de gestão que se baseiam no cálculo da "pegada ecológica" e na preservação da biodiversidade. Polanyi vê nessas três perspectivas uma oportunidade de "aumentar nossa liberdade de adaptação criativa e, assim, aumentar nossas chances de sobrevivência". (CHAVANCE, 2OII, p. IX) Tudo isso destaca a atualidade e relevância do pensamento de Polanyi para a reflexão organizacional (HILLENKAMP; LAVILLE, 20I4) e nos convida a repensar os próprios fundamentos da teoria das organizações. É justamente nessa tarefa que um autor brasileiro, Guerreiro Ramos, se engaja.

\section{ORGANIZAR A SOLIDARIEDADE REPENSANDO SUA RACIONALIDADE: A CONTRIBUIÇÃO DE GUERREIRO RAMOS}

A obra de Guerreiro Ramos é ambiciosa na medida em que se propõe a criar uma "nova ciência das organizações". (GUERREIRO RAMOS, 1984) O fundamento epistemológico da sua abordagem é de natureza substantiva. Nisso, ele se junta a Polanyi, cuja contribuição ele reconhece. Guerreiro Ramos pensa que "a ciência social moderna foi concebida com o objetivo de libertar o mercado de cadeias que, através da história da humanidade até o surgimento da revolução comercial e industrial, a manteve confinada dentro de limites definidos". (GUERREIRO RAMOS, I984, p. 22) Guerreiro Ramos propõe, de fato, complementar e ampliar, no campo organizacional, o trabalho iniciado por Polanyi no campo econômico. Ele nega aos teóricos da economia ortodoxa sua reivindicação à universalidade. Ele afirma, como Polanyi, que a economia sempre foi incorporada na sociedade e que, portanto, a sociedade capitalista deve ser entendida e abordada como um caso excepcional. Também como 
Polanyi, ele se refere a pensadores clássicos como Platão e Aristóteles para afirmar a primazia da política sobre a economia, a fim de garantir uma vida boa. Ele articula seu pensamento sobre questões organizacionais substantivas através da proposição de vários conceitos originais, conforme abordaremos a seguir.

\section{Poder e condicionamento das organizações formais}

Guerreiro Ramos considera que as organizações formais hoje têm muito poder. Essa ideia pode parecer, à primeira vista, um achado comum. Não se contesta, de fato, a enorme ascensão das organizações de mercado no mundo de hoje e muitos são aqueles que criticam esse alto poder. A riqueza e profusão da literatura acadêmica na teoria das organizações são, além disso, um sinal evidente de tais debates. No entanto, a originalidade do pensamento de Guerreiro Ramos é que ele não está interessado no poder das organizações dentro da esfera econômica do mercado, mas fora dele. Para ele, esse poder é de fato expresso por um condicionamento da sociedade, que ele considera prejudicial. Não se deve, todavia, buscar no trabalho de Guerreiro Ramos qualquer tentativa de análise conspiratória ou uma análise dos métodos de comunicação de massa empregados pelas empresas. Sua análise é bem diferente. Ele se esforça para demonstrar com rigor e fineza, através de análise semântica rigorosa, a existência de um processo de condicionamento lento, indireto, muitas vezes, não consciente e profundamente poderoso.

O ângulo de entrada da sua reflexão é a questão da racionalidade. Toda teoria das organizações está orientada segundo esta questão central, com dois fortes momentos na história do pensamento. Antes de Simon, a racionalidade é objeto de um conhecimento absoluto. Ela é conduzida por indivíduos que arbitram nos mercados, fazendo escolhas e tomando decisões. Em cada estágio, a racionalidade guia seus passos. Ela os torna atores econômicos. Em contrapartida, todos esses atos racionais ajudam a garantir o equilíbrio do mercado, as possibilidades de ajuste e a regulação econômica. Depois de Simon (1955), essa racionalidade dos atores humanos se torna limitada. Ela não pode mais 
ser conduzida ou encarnada por indivíduos isolados. Agora, o conhecimento perfeito não está ao alcance deles. Se a racionalidade não desapareceu, ela está, contudo, deslocada. Parece que os homens não podem mais suportar sozinhos a "tocha da razão". A complexidade das decisões a serem tomadas se confronta com as limitações inerentes às suas capacidades cognitivas. A organização coletiva irá, portanto, substituí-los e preencher sua deficiência. Para Simon, a informatização das organizações oferece a oportunidade de buscar um conhecimento perfeito. O aumento de poder de arquiteturas informáticas pleiteia a possibilidade de tratamento de dados sem limites. Esse deslocamento da responsabilidade da racionalidade do homem para a máquina é muito interessante notar. Ele pressupõe, com efeito, um continuum entre o homem e a máquina, mas enfatiza sobretudo o caráter calculista da racionalidade.

Há, segundo Guerreiro Ramos, um erro de pensamento. Sua origem é antiga, pois Guerreiro Ramos volta a Hobbes, a quem ele critica por ter sido o iniciador deste reducionismo de compreensão da razão. Rebaixando o homem a um ser calculista, bloqueia-se a capacidade de distinguir o vício da virtude. Essa extração da dimensão ética para fora da racionalidade é característica do pensamento organizacional dominante. A irrupção da informática no debate é ilustrativa: o próprio de um algoritmo econômico é de calcular e não se colocar questões morais. Nenhum valor superior altera ou interrompe sua sequência de operações lógicas. Assim, as organizações formais caracterizam-se sobretudo pela otimização de meios em relação aos fins. Para elas, a racionalidade está subordinada às necessidades objetivas inerentes aos processos de produção implantados. Aí está, para Guerreiro Ramos, a fonte do condicionamento.

Para demonstrarisso, ele se concentra em dartraduções semânticas. Assim, a questão do trabalho é, geralmente, reduzida à noção de emprego. Ter um emprego significa ter um salário, um contrato, treinamento, um enquadramento no interior de uma organização formal. O emprego, portanto, tem uma virtude em si. Ele introduz o empregado na vida das organizações e fornece-lhe uma renda fixa em troca. Graças a isso, ele pode se tornar um consumidor e comprar bens e serviços produzidos por essas mesmas organizações. Smith, antes de 
Ford, havia antecipado essa sequência quando escreveu na riqueza das nações que a divisão do trabalho leva todos a se tornarem comerciantes. (SMITH, I988) Em referência ao "doce comércio" de Montesquieu, existe para Smith uma cadeia virtuosa que transforma a sociedade em uma sociedade de mercado. Mas, para Guerreiro Ramos, a substituição da noção de emprego pela de trabalho tem uma contrapartida: ela invisibiliza todo o trabalho realizado fora da noção de emprego. São assim rejeitados para o espaço não econômico tudo o que não pode ser considerado como um recurso ou uma produção. Rejeita-se, portanto, as atividades realizadas no âmbito da família, da culinária, do lar, do esporte, da jardinagem, do tempo com os amigos, do cuidado com os seus, do engajamento cívico e das atividades voluntárias. Assim, tudo relacionado ao desenvolvimento pessoal ou à reprodução é colocado fora do campo econômico. O que há, então, além do emprego? Guerreiro Ramos mostra que a sociedade de mercado criou um conceito para o que está fora do trabalho: o lazer. Ele é sinônimo de ociosidade, relaxamento, isto é, de inatividade. O mercado oferece os serviços associados a essa inatividade por meio de uma economia do lazer. É um pouco como se o mercado não pudesse pensar em um espaço fora de si mesmo. Guerreiro Ramos se diverte lembrando que o sentimento de ociosidade na Grécia antiga era um estado onde o lazer em sua versão moderna não seria possível. Para os antigos gregos, a ociosidade - otium - era de fato um estado de calma interior, distanciamento e ambiente de estudo, longe da indolência frívola de uma economia do lazer.

\section{A síndrome comportamentalista induzida pela organização formal}

Por trás desse deslocamento semântico, Guerreiro Ramos supõe a existência de uma síndrome comportamentalista. Os indivíduos não seriam insensíveis às prescrições organizacionais e a doxa econômica disseminada dentro de organizações formais. Um longo processo de interiorização inconsciente seguiria até se tornar uma segunda natureza. O indivíduo estaria, então, pronto para se tornar o que Guerreiro Ramos chama de "criatura fluida", 
isto é, um ser sujeito ao fluxo constante de injunções e critérios utilitários avançados pelas empresas. Para Guerreiro Ramos, as empresas fazem uma inversão de significado por serem capazes de considerar as situações apenas a partir do ângulo funcional. Diante disso, os indivíduos empregados nas empresas enfrentam um dilema: aderir totalmente às demandas da organização ou simular essa adesão. No primeiro caso, há potencialmente uma desorientação, anomia e perda de valores. No segundo, é necessário ser capaz de gerenciar uma identidade múltipla com um comportamento diferente em sua vida profissional e em sua vida pessoal. O resultado é um possível maquiavelismo, ou um vetor de angústia e de estresse.

Para Guerreiro Ramos, portanto, há consequências políticas e psicológicas em função do domínio da racionalidade instrumental nas sociedades modernas. Segundo ele, a subjetividade individual é prisioneira da racionalidade instrumental. Ele considera que o capitalismo limita a possibilidade de comunicação livre e autêntica entre indivíduos. Organizações formais usam, consciente ou inconscientemente, uma "linguagem distorcida" com a intenção de levar as pessoas a interpretar a realidade em termos que beneficiem os agentes diretos ou indiretos dessa distorção. (GUERREIRO RAMOS, 1984) É por isso que Guerreiro Ramos é muito crítico da escola de relações humanas, acusando seus teóricos de legitimar a expansão de organizações formais falando de confiança, autenticidade, mente aberta e praticando um "humanismo mal colocado e incompreendido". (GUERREIRO RAMOS, I984, p. 83) Para ele, as empresas organizadas em torno da busca do lucro não podem ser o lugar para uma expressão autêntica dos indivíduos ou uma possível coincidência entre os objetivos das organizações e os indivíduos que eles empregam. Não podemos, portanto, lutar contra a alienação, que é um sentimento de impotência e de perda de sentido que causa isolamento e marginalização, simplesmente mudando o tipo de tecnologia usada. Não podemos mais lutar contra a anomia, buscando re-humanizar as empresas. Para Guerreiro Ramos, há uma incompatibilidade irredutível nessa tentativa porque "o desenvolvimento pessoal e a solidão são inseparáveis". (GUERREIRO RAMOS, 1984, p. 98) 
Um dos riscos que pesam sobre o equilíbrio psicológico dos indivíduos é a superorganização. Essa superorganização vem da pressão das lógicas de mercado sobre os tempos da vida pessoal. A organização excessiva, portanto, tem um impacto significativo na despersonalização do indivíduo. Guerreiro Ramos aponta que a educação não está imune a essa pressão e está cada vez mais voltada para capacitar os estudantes a encontrar um emprego no sistema de mercado. As necessidades do homem são múltiplas e o sistema de mercado responde apenas de forma limitada. Para o mercado, é uma questão de padronizar as necessidades para fazê-las entrar em sua grade de referência. Para isso, é necessário um condicionamento dos indivíduos. Sua finalidade é, entre outras coisas, achatar o espaço, linearizar o tempo e transformar a razão em cálculo.

\section{A razão instrumental das organizações formais}

Com base nessa análise semântica e na descrição da síndrome comportamentalista, Guerreiro Ramos permite se lançar numa crítica frontal. A teoria da organização como a conhecemos "é ingênua porque pressupõe uma racionalidade instrumental inerente à ciência social ocidental". (GUERREIRO RAMOS, I984, p. 3) Essa crítica é dirigida principalmente a autores que tentaram "legitimar a sociedade moderna unicamente sobre as bases utilitárias". (GUERREIRO RAMOS, I984, p. 5) Segundo Guerreiro Ramos, o conceito de racionalidade é central na análise porque condiciona toda a abordagem das questões sociais. Guerreiro Ramos se insurge contra a ideia de que o conceito de razão possa se alinhar com o quadro normativo da sociedade moderna. Para esse autor, a racionalidade desaparece em um mundo em que meios e fins se tornam as únicas referências da ação humana. Ao mesmo tempo, defende a racionalidade contra o que ele chama de "anti-racionalidade mal definida", entendida como "uma das teses daqueles que se definem como humanistas" (GUERREIRO RAMOS, I984, p. 5), sem, entretanto, abandonar seu quadro normativo.

Guerreiro Ramos reprova a tradição iluminista por sua confiança no progresso. Ele, então, critica Marx por confiar no desenvolvimento das forças 
produtivas para garantir a emancipação e a liberdade. Ele rejeita a ideia hegeliana - assumida por Marx - de uma evolução histórica que permitiria que a razão pura se conformasse à razão prática. Com Horkheimer, ele argumenta que "a denúncia do que hoje é chamado de razão é o maior serviço que a razão pode prestar". (HORKHEIMER, I947, p. I87) Para Guerreiro Ramos, o indivíduo moderno está principalmente ocupado expressando intenções e não sabe usar a linguagem para transmitir o significado. Além disso, a razão que Guerreiro Ramos defende não se deixa apreender-se de forma simples. Existe na razão um impulso inerente que condiciona a possibilidade dessa mesma razão.

Ele compartilha assim a tese de Voegelin de que a modernidade é portadora de uma violenta tentativa política de invocar o paraíso na Terra, afirmando uma doxa sobre a forma que esse paraíso deve assumir. A violência é dupla na medida em que a imposição do paraíso anda de mãos dadas com o desejo de mantê-lo contra tudo. Para Voegelin, a corrupção de tal proposição é intrínseca e não pode pretender escapar à lei cíclica do declínio e queda. Para sair dessa visão gnóstica, Voegelin se refere aos antigos. Isso mostra que a noção aristotélica de boa sociedade não é de modo algum unívoca e não é reduzida a uma única ocorrência. Ela é objeto de uma adaptação levando em conta as circunstâncias e o contexto, além de uma escolha de arbitragem entre vários cenários possíveis. Guerreiro Ramos encontra nessa ideia argumentos para uma visão multicêntrica da organização.

Guerreiro Ramos sustenta ainda um segundo argumento com Voegelin. A ideia do paraíso e do aqui abaixo são os dois pólos de uma tensão existencial irredutível. A razão não pode ser pensada sem a consciência dessa tensão. Ao considerar a possibilidade de um paraíso na terra, a razão moderna procede não apenas de uma experiência distorcida da realidade, mas se desqualifica. Negligenciando essa tensão inerente à condição humana, a razão moderna perde seu próprio élan e, para Voegelin, sua força qualificadora e criativa. No entanto, apesar de retomar estas críticas à razão moderna, Guerreiro Ramos critica em Voegelin o fato de não nos dar qualquer indicação sobre as implicações operacionais dessas proposições filosóficas em relação à sociedade contemporânea. 


\section{A defesa da racionalidade substantiva}

Para ir além da crítica da racionalidade do mercado, Guerreiro Ramos tem necessidade de propor uma alternativa. Ele vai buscá-la em Max Weber. Este último fornece argumentos para defender uma racionalidade diferente da racionalidade instrumental moderna. Guerreiro Ramos ressalta o quanto Weber é condicionado pelo seu tempo vendo a burocracia como o exercício de funções racionais no contexto particular de uma sociedade de mercado capitalista. No entanto, ele retém de Weber a distinção entre racionalidade formal e material. Como vimos, a primeira pode se exprimir através do raciocínio numérico ou contábil, já a segunda, leva em consideração outros requisitos em termos de valores ou propósitos. (WEBER, I97I, p. I3I) Guerreiro Ramos mantém a segunda como sua base de trabalho e ela parece consistente com as ideias defendidas por Voegelin. Ele qualifica a racionalidade material como racionalidade substantiva.

Para sustentar a solidez da racionalidade substantiva que ele defende, Guerreiro Ramos se volta para Habermas. Este autor está interessado naquilo que permite que uma sociedade continue a produzir coesão e sentido e analisa como isso remete à interação simbólica. Habermas propõe, assim, uma distinção entre uma ação racional aplicada - pela vocação instrumental - e uma ação comunicativa - situada na interação simbólica. A primeira, refere-se a regras técnicas e pode ser verdadeira ou falsa. A segunda, baseia-se em relações interpessoais livres de restrições externas e fundamenta-se na intersubjetividade e compreensão mútua. Portanto, a preponderância da racionalidade instrumental nas sociedades modernas só pode ser entendida através da existência de uma comunicação distorcida.

A superioridade do mundo capitalista sobre os modos que o precederam foi imposta por dois meios principais: um mecanismo econômico baseado na expansão permanente e a legitimação dessa expansão no campo político para transformar as necessidades. Esta ideia refere-se ao processo de racionalização descrito por Weber. Mas, para Guerreiro Ramos, Habermas não coloca valores morais entre parêntese, como faz Weber. Ao colocar a racionalidade 
no espaço da comunicação, Guerreiro Ramos acredita que Habermas implementa uma teoria social crítica integrada que possibilita, ao mesmo tempo, uma melhor compreensão dos mecanismos de coerção e da possibilidade de considerar a emancipação. Com essa proposta de conceito de racionalidade substantiva baseada na reflexão da Escola de Frankfurt, Guerreiro Ramos pôde vislumbrar uma extensão do seu pensamento.

\section{O conceito de paraeconomia}

Guerreiro Ramos avança o conceito de paraeconomia para poder descentralizar a análise. (FRANÇA FILHO, 20I0) Ele procura, com efeito, mostrar que as dinâmicas organizacionais não se limitam aos mecanismos e à lógica de mercado. A paraeconomia, portanto, ajuda seu autor a se afastar e mostrar que o mercado não é mais que um enclave social, entre outros. O que Guerreiro Ramos busca através do conceito de paraeconomia é construir uma teoria política substantiva para melhorar de forma qualitativa a vida social dos indivíduos. Para ele, "todo cidadão que busca promover cenários alternativos aos sistemas centrados no mercado é, portanto, um para-economista". (FRANCA FILHO; BOULLOSA, 2015, p. 213) Por trás desses cenários alternativos, o desejo de Guerreiro Ramos é promover o desenvolvimento e o reconhecimento de isonomias e fenonomias como arranjos institucionais essenciais para uma sociedade mais viável e sustentável. Para Guerreiro Ramos, toda teoria organizacional extensiva pressupõe necessariamente uma ciência social com a mesma natureza epistemológica. Se o equivalente da teoria organizacional atual é a ciência social formal, o que ele chama de nova ciência das organizações é a ciência social substantiva. (GUERREIRO RAMOS, 1984)

Nessa perspectiva, Guerreiro Ramo propõe seu paradigma paraeconômico enquanto modelo multicêntrico para análise e planejamento dos sistemas sociais. (FRANÇA FILHO 20IO e 20I9) Neste, Guerreiro Ramos distingue dois eixos. No primeiro eixo, ele parte da anomia - ou ausência de normas - em direção à prescrição. Anomia é um conceito avançado por Durkheim. Guerreiro Ramos aproveita para designar indivíduos sem normas que não têm o sentido da relação com o outro. O indivíduo anômico é, portanto, uma pessoa incapaz 
de criar um ambiente social que lhe permita subsistir. A anomia como princípio de desorganização - num extremo - é oposta à economia - no outro extremo - que valoriza justamente o trabalho de padronização ou normalização em torno da produção de bens e serviços. O indivíduo anômico é incapaz de criar um ambiente social que possa atender às exigências do mercado. Para Guerreiro Ramos, o indivíduo anômico deve ser assistido, protegido e até mesmo controlado por organizações ad hoc - associações, centros educacionais, centros de saúde, prisões etc. Nesse sentido, a anomia também exige uma reflexão organizacional que deve ser levada em conta no quadro paraeconômico.

Se no primeiro eixo o intuito foi de opor uma situação de absoluta falta de normas, num extremo, com um estado de total prescrição, no outro, já no segundo eixo, que cruza o primeiro em seu centro, Guerreiro Ramos contrasta o critério da orientação pessoal com o da orientação comunitária. Seu intuito é de permitir refletir para além da oposição clássica entre o individualismo do mercado, de um lado, e o coletivismo do marxismo, do outro. Esse quadro geral da paraeconomia em dois eixos permite relativizar o modelo organizacional do mercado e abrir uma possível visão emancipadora das teorias da organização. Ele possibilita igualmente tornar visível formas organizacionais deslegitimadas ou marginalizadas pelo mercado. Por fim, permite ainda um trabalho de redefinição de categorias usuais que a economia de mercado banalizou.

Figura 1 - O paradigma paraeconômico

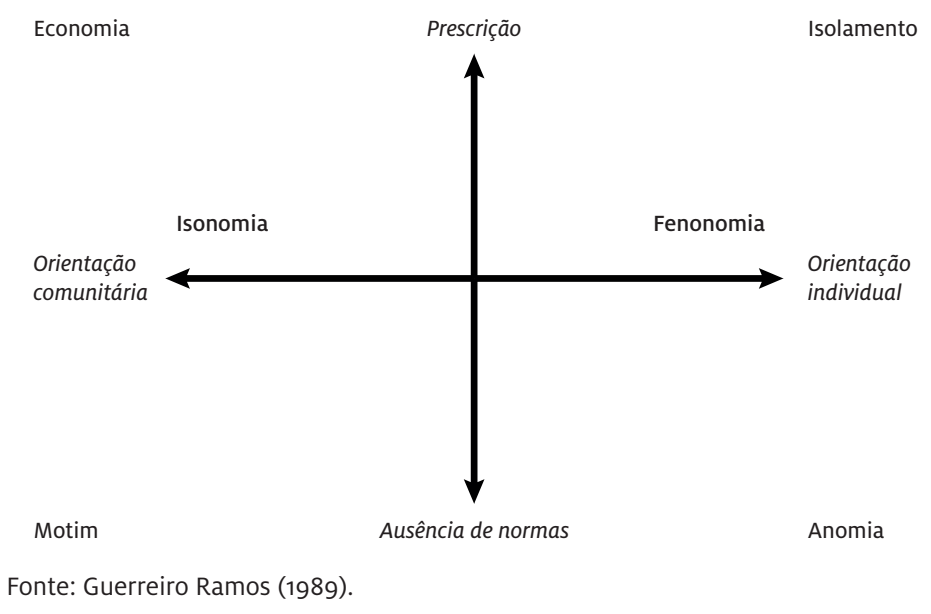




\section{A fenonomia}

A organização pessoal resulta na existência de fenonomias oferecendo aos indivíduos a máxima liberdade de escolha pessoal e garantindo ao mesmo tempo uma subordinação mínima a restrições operacionais. É, para Guerreiro Ramos, um "ambiente novo, temporário ou mais ou menos estável, iniciado e liderado por um indivíduo ou um pequeno grupo. Ele oferece aos seus membros um máximo de escolha pessoal e um mínimo de subordinação às prescrições operacionais". (GUERREIRO RAMOS, I984, p. I32) Esse ambiente permite grande criatividade e autoriza seus membros se envolverem apenas em trabalhos escolhidos por eles mesmos. Pode ser uma paixão pessoal mantida em um espaço para si mesmo, como um local da casa que reservamos para a bricolagem ou um ateliê de criação. Tudo é feito para que os indivíduos expressem sua criatividade e autonomia. Os membros de uma fenonomia são pessoas criativas e autônomas que geralmente dispõem de uma força interior que os impulsiona a agir. Eles são, portanto, capazes de executar seus projetos e seguir sua vocação no contexto de uma trajetória pessoal e isolada. No entanto, o ambiente oferecido por uma fenonomia é tanto protetor quanto favorável. Cada membro de uma fenonomia pode, assim, compartilhar recursos materiais e imateriais e aproveitar a dinâmica criativa do coletivo.

Guerreiro Ramos aponta quatro condições para a implementação de uma fenonomia: a primeira, é dispor de um ambiente propício à expressão da criatividade sob formas escolhidas. Em tal ambiente, a criação pode ser indiferentemente a ocasião de um trabalho individual ou em um pequeno grupo; em segundo lugar, os membros de uma fenonomia só se envolvem em trabalhos escolhidos por eles mesmos, isso significa que eles são capazes de construir sua própria agenda e definir suas próprias prioridades. Como as tarefas são escolhidas livremente, cabe à pessoa que as define assumir as regras de operação e as especificações; terceiro, se o resultado das atividades realizadas no contexto de uma fenonomia for colocado no mercado, os critérios econômicos permanecem secundários para seus membros. As fenonomias são ambientes sociais que se protegem das incursões de mercado. Podemos 
mesmo dizer que uma fenonomia visa confrontar e se sobrepor ao sistema de mercado. Portanto, os membros de uma fenonomia não contam seu tempo; quarto e último ponto, o membro de uma fenonomia tem uma sensibilidade social que não trai seu desejo de ter uma criação original. Ele não deseja se retirar da sociedade, mas sim sensibilizar os outros para experiências que eles poderiam compartilhar e apreciar.

\section{A isonomia}

Guerreiro Ramos chama isonomia uma "associação de iguais constituída para proporcionar uma vida boa" - no sentido de Aristóteles, isto é, uma vida feliz. Guerreiro Ramos define cinco princípios para as isonomias. O primeiro é permitir o desenvolvimento dos seus membros sem prescrições impostas. Os membros são associados livremente nas isonomias para realizar ações gratificantes. As prescrições são mínimas e, quando não podem ser evitadas, elas são estabelecidas por consenso. Em segundo lugar, o engajamento dentro de uma isonomia é altamente recompensador na medida em que conduz à livre associação de indivíduos em torno de projetos considerados por si próprios como dignos de interesse. O poder das isonomias reside na criação de fortes relações interpessoais entre os membros. A vida do grupo é reforçada por laços de convivialidade. Não se entra numa isonomia com a intenção de ganhar a vida, mas participar de uma reciprocidade generosa e expressar uma vocação. Em terceiro lugar, a recompensa vem da conclusão do projeto e não da atividade monetária que pode derivar dele. A abordagem não é, portanto, utilitária, e os indivíduos não procuram maximizar qualquer função de utilidade. Em quarto lugar, uma isonomia é uma organização comunitária que supõe um sistema de tomada de decisões estritamente igualitário, no qual a autoridade passa continuamente de pessoa para pessoa, dependendo da natureza dos projetos e das competências dos seus membros. Nela, não há divisões ou diferenças entre os membros. Na isonomia, se pensa e se vive como uma comunidade em que a autoridade se funda na deliberação comum. Como não há uma agência dirigente imutável e exclusiva, Guerreiro Ramos se 
recusa a considerar a isonomia como uma democracia representativa. Isso o leva a pensar em um quinto princípio segundo o qual, quando o tamanho de uma isonomia cresce, ela é sistematicamente transformada em uma oligarquia ou em uma burocracia. Nisso ele se junta à lei de ferro enunciada por Michels (1915). A isonomia é de fato dependente da força das relações interpessoais existentes entre os membros.

\section{Para uma sociedade multicêntrica}

A partir do esquema dado pelo quadro paraeconômico e de acordo com a caracterização das formas isonômicas e fenonômicas, Guerreiro Ramos formula a possibilidade de uma sociedade multicêntrica, conforme sua própria definição. Para Guerreiro Ramos, a proposta de um paradigma paraeconômico é antes de tudo uma resposta à emergência e às necessidades da sociedade pós-industrial. A sociedade multicêntrica que ele associa a esse paradigma implica na redefinição da noção e do papel do Estado. Este último deve ser capaz de distinguir em sua ação o que vem do mercado e o que não pertence a ele. Isso envolve a criação de políticas de alocação específicas que apoiem "ambientes sociais propícios ao crescimento pessoal, às relações conviviais e às atividades coletivas dos cidadãos". (GUERREIRO RAMOS, I984, p. 152) Guerreiro Ramos propõe orientar essa ação pública pelo que apresenta como uma nova lei das organizações, designada por ele então sob o termo "lei da adequação necessária". (GUERREIRO RAMOS, I984, p. I35) Essa lei estabelece o princípio de que qualquer sociedade responsável pela realização pessoal de seus membros deve preservar a variedade dos sistemas sociais e garantir a independência de suas formas específicas de organização.

Ele afirma que nenhuma sociedade se encontrou no passado numa situação idêntica à nossa. Ele adverte que o nosso "processo de socialização está sujeito a uma política cognitiva exercida por grandes interesses privados que escapam a todo controle". (GUERREIRO RAMOS, I984, p. I63) A implementação de uma "sociedade multicêntrica" (FRANÇA FILHO, 20IO; FRANÇA FILHO; BOULLOSA, 20I5) supõe então, para Guerreiro Ramos, uma resistência em rela- 
ção à hegemonia de uma sociedade de mercado que invadiu o espaço vital dos indivíduos. Para Guerreiro Ramos, como para Polanyi, não se trata de suprimir o mercado, mas de relativizá-lo. Para isso, ele precisa retornar às categorias usuais que o mercado reduz a visões funcionais. É assim, segundo ele, para tecnologia, tamanho, cognição, espaço e tempo. A sociedade multicêntrica supõe de fato revisitar essas noções usuais. (FRANÇA FILHO, 20IO; FRANÇA FILHO; BOULLOSA, 20I5)

A tecnologia desempenha um papel determinante nas sociedades humanas. Por isso, é particularmente importante entender sua lógica. Trata-se, especialmente, de ser capaz de harmonizar o desenvolvimento tecnológico com o equilíbrio dos nossos sistemas sociais. Essa constatação está em consonância com o trabalho de inovação social que denuncia o domínio das empresas sobre as inovações tecnológicas e o mercado que as carrega. (KLEIN; LAVILLE; MOULAERT, 20I4) Guerreiro Ramos procura compreender como o desenvolvimento tecnológico pode se libertar dos fins do mercado para servir "populações locais cuja intenção não é precisamente responder às demandas do mercado". (FRANÇA FILHO; BOULLOSA, 20I5, p. 2II) Não se pode esquecer aqui de fazer referência ao software livre e em particular a experiência Flok - Free Libre Open Knowledge - no Equador. Este, foi iniciado em 2ori por um grupo de ativistas espanhóis em colaboração com um ministro do governo equatoriano. A ideia era implantar a cultura digital livre em uma estrutura cidadã e democrática com o mínimo de recursos naturais. O Flok é o primeiro projeto a ter essa ambição no nível de um país inteiro. Ao longo do projeto, comunidades locais intercambiaram com grupos de hackers para desenvolver uma cultura e um saber comuns.

Para Guerreiro Ramos, o tamanho refere-se ao número de pessoas necessárias para implementar um cenário social. Para ele, aumentar o tamanho não é um pré-requisito. A busca pelo tamanho certo depende do sistema social a ser considerado e de suas ambições. No entanto, Guerreiro Ramos observa que o mercado - assim como o Estado - tende a privilegiar o efeito de escala em favor do aumento de tamanho, enquanto as isonomias são forçadas a manter um tamanho pequeno para não desaparecer. 
A cognição é importante para Guerreiro Ramos na medida em que se refere à ligação que ele considera crucial entre a diversidade de saberes e o conhecimento próprio dos sistemas sociais. A prevalência de esquemas cognitivos derivados da lógica de mercado empobrece indivíduos e enfraquece sua capacidade de liberar sua própria criatividade - em fenonomias - ou de cooperar em um plano de igualdade - em isonomias. Para quebrar hierarquias, que também são hierarquias de saberes, a abordagem de Guerreiro Ramos é semelhante às abordagens de educação popular desenvolvidas na América do Sul. (FREIRE, 1994)

Já no que diz respeito ao espaço, esse foi transformado pela lógica de mercado, conforme salienta Guerreiro Ramos. Como prova disso, o desenvolvimento urbano foi feito principalmente de acordo com as necessidades do mercado. Guerreiro Ramos enfatiza a ligação entre o espaço assim transformado e a percepção do homem. Ele observa que "o espaço pode nos ajudar, ou nos atrapalhar, relaxar nossas tensões ou nos criar estresse". (GUERREIRO RAMOS, 1984, p. I42) Guerreiro Ramos acredita que as exigências espaciais específicas são inerentes à cada tipo de ambiente social. Para ele, o uso, sabiamente, do espaço em cada um dos sistemas sociais é uma ferramenta a serviço de um melhor equilíbrio psicológico. Assim, preocupações como "solidão, privacidade, reserva, intimidade, anonimato, território pessoal" (GUERREIRO RAMOS, I984, p. I45) podem ser gerenciadas através de uma justa consideração do espaço. Guerreiro Ramos acredita na contribuição de antropólogos e psicólogos para criar espaços socioaproximadores, ou seja, espaços capazes de colocar a sociedade e o social no centro da organização. Por definição, isonomias e fenonomias são espaços socioaproximadores. Como tais, eles têm o poder de "ressocializar indivíduos anômicos". (GUERREIRO RAMOS, 1984, p. I46) Por outro lado, a maioria das empresas mercantis são espaços socioafastadores, que rejeitam o social para fora do campo organizacional.

O tempo é invocado por Guerreiro Ramos como fator a ser privilegiado para garantir a possibilidade de uma sociedade multicêntrica. Ele mobiliza a teoria da multiplicidade de tempos sociais promovida por Gurvitch (I968) 
para relativizar o tempo sequencial ou linear como única referência do mercado e para encontrar os tempos em conexão com o indivíduo, ou seja, aqueles que favorecem a criatividade pessoal, aqueles que não são quantificáveis. O tempo de convivência, por exemplo, é catártico e promove confiança e a expressão sincera. Por favorecer as relações interpessoais, a isonomia anda de mãos dadas com a convivialidade. A experiência do tempo não se limita a uma medida quantitativa. Guerreiro Ramos recusa, assim, "a unidimensionalidade do tempo que vitima a maioria das pessoas que vivem em um sistema de mercado" (GUERREIRO RAMOS, I984, p. I50), provocando ainda o aumento do estresse e da alteração psíquica. Ele propõe "políticas paraeconômicas" para derrubar a primazia atual e fazer com que o tempo do mercado esteja submetido à temporalidade social.

\section{Para uma nova ciência das organizações}

A urgência de Guerreiro Ramos para fundar uma nova ciência das organizações surge da constatação da sensibilidade do nosso mundo às externalidades negativas, sejam elas ambientais ou psicológicas, produzidas por atividades não reguladas do mercado. Segundo Guerreiro Ramos, a obsessão pelo emprego como único critério para avaliar a saúde econômica é um erro fundamental dos governantes e seus economistas. Para ele, a economia não se resume a atividade de mercado. Também é forte todas as atividades fora do mercado que contribuem para a qualidade de vida e participam do seu aprimoramento. Neste campo paraeconômico, "os recursos são infinitos e a produção não tem limite". (GUERREIRO RAMOS, I984, p. I56) Eles são nutridos pela reciprocidade. Exemplos dessas produções paraeconômicas podem ser encontrados nas atividades de associações, comunidades e famílias. Essas atividades, geralmente, buscam suprir as necessidades não satisfeitas - ou parcialmente satisfeitas - pelo Estado e pelo mercado. Algumas necessidades também podem estar sujeitas ao esquecimento voluntário (ou não). A contribuição dessas atividades se mede antes de tudo no contexto de uma contribuição na escala do conjunto da sociedade. Guerreiro Ramos mostra que uma 
avaliação contábil convencional não é pertinente, pois não pode contabilizar todo o valor produzido. Como tal, é preferível se desvincular da lógica do mercado. Guerreiro Ramos pensa com efeito que, para essas atividades, a subvenção é o modo de financiamento requerido e apropriado.

Nesse sentido, Guerreiro Ramos propõe um modelo multidimensional de análise e concepção dos sistemas sociais, no qual o mercado é considerado "um enclave social, legítimo e necessário, permanecendo limitado e controlado". (GUERREIRO RAMOS, I984, p. I58) De fato, o mercado só pode mascarar e esmagar as múltiplas dimensões da vida pessoal e a variedade de interações sociais. Para Guerreiro Ramos, parece então difícil conciliar a realização pessoal e o utilitarismo no sentido econômico formal. Se queremos garantir as duas coisas ao mesmo tempo - porque as consideramos como imperativas da vida social -, então, é necessário definir os enclaves, em que cada um pode funcionar satisfatoriamente. Guerreiro Ramos pensa na construção de sistemas sociais como uma ciência multidimensional, e avança na ideia de que "viver de acordo com o paradigma para-econômico é uma arte multidimensional". (GUERREIRO RAMOS, I984, p. I23)

Ele deduz uma estrutura multidimensional para a tomada de decisões na qual a lógica de mercado não tem pertinência fora do perímetro que é o seu. Para evitar seu transbordamento, é uma questão de controlar seu confinamento. Guerreiro Ramos pretende, assim, preservar a possibilidade de um desenvolvimento humano que é, para ele, inversamente proporcional ao tempo gasto no universo do consumo de bens. Guerreiro Ramos vê nas atividades produtivas que estimulam o engajamento cívico e o sentimento coletivo os verdadeiros vetores da qualidade de vida de uma nação. Portanto, todo o desafio do desenvolvimento humano é conseguir garantir a essas atividades e às formas organizacionais que as promovem, as condições necessárias para sua existência, sua perenidade e sua autonomia. Para definir tais políticas públicas, é importante preservar a diversidade de estruturas de tomada de decisão e as racionalidades relacionadas. Assim, fica claro para Guerreiro Ramos que a lógica formal do mercado não tem qualquer validade para julgar ou avaliar 
atividades não mercantis. Isso seria até mesmo contraproducente. Defender uma sociedade multicêntrica significa defender um modelo multidimensional que legitima as abordagens e a racionalidade substantiva. Como tal, as fronteiras devem ser impermeáveis entre o que ele chama de enclaves. Por exemplo, uma associação não pode ser julgada com base na lucratividade ou produtividade e se deva exigir que ela seja financeiramente autossuficiente. E, claramente, o desenvolvimento do mercado deve ser regulado politicamente de modo a não minar a base dos enclaves isonômicos e fenonômicos.

\section{ORGANIZAR A SOLIDARIEDADE PELA BUSCA DO PLURALISMO}

A interação simbólica promovida por Guerreiro Ramos supõe que a realidade social se torne inteligível através de experiências liberadas de restrições e da lógica do mercado. Estas bloqueiam efetivamente as trocas genuínas e a proximidade entre as pessoas, mantendo uma artificialidade nas relações sociais. Essas experiências fora do mercado são ainda mais necessárias já que cada indivíduo "participa da fabricação da realidade social". (GUERREIRO RAMOS, I984, p. III) Ao revelar isonomias e fenonomias, a abordagem substantiva das organizações proposta por Guerreiro Ramos participa, então, de uma vontade de preservar o pluralismo.

A crítica que Guerreiro Ramos desenvolve em relação à razão moderna não se pretende abrupta. Guerreiro Ramos não rejeita em bloco a razão. Ela é para ele um conceito básico de qualquer ciência da sociedade e das organizações. No entanto, ele pretende ampliar o quadro analítico para estendê-la à vida pessoal e social. Sua ambição é abrir uma outra via para o desenvolvimento de uma nova ciência das organizações, a fim de superar uma racionalidade funcional - a serviço das populações ocidentais - que busque dominar a natureza e aumentar a capacidade de produção. Nisso, ele denuncia simultaneamente o caráter ocidentalo-centrista e o reducionismo do pensamento utilitarista, para favorecer a tomada de consciência e abrir novas perspectivas intelectuais. 
Para Guerreiro Ramos, a racionalidade substantiva está no coração da psique humana. Ele propõe então que essa psique seja considerada como referência na organização da vida social. Sua abordagem é uma "declaração preliminar para a nova ciência das organizações". No entanto, ele está ciente de que "ainda há muito a ser feito para transformar a nova ciência em uma ferramenta para a reconstrução social". (GUERREIRO RAMOS, I984, p. I69) Como autor brasileiro, Guerreiro Ramos denuncia o caráter ocidentalo-centrista da teoria das organizações e das ciências sociais em geral. Ele enfatiza que essas ciências não gostam de reconhecer a viabilidade intrínseca das sociedades não ocidentais e tendem a considerar a ocidentalização dessas sociedades como uma garantia de qualidade. Guerreiro Ramos observa ainda que o processo de institucionalização "de uma sociedade multicêntrica está em curso, de forma desordenada e em múltiplas formas". (GUERREIRO RAMOS, I984, p. I55) No entanto, esse processo precisa ser apoiado. Para Guerreiro Ramos, "apenas uma revolução organizacional global pode deter a destruição do planeta e mudar as condições de vida". (GUERREIRO RAMOS, I984, p. I64)

Vimos, neste capítulo, a importância do quadro analítico polanyiano para pensar uma economia compatível com a organização da solidariedade. O quadro oferecido pela economia substantiva nos permite conectar dois campos que a visão ortodoxa da economia de mercado nunca parou de separar: a política e a economia. Ele também ajuda a relativizar a importância do mercado, revelando o que o mercado invisibiliza ou combate: a redistribuição, a reciprocidade e compartilhamento doméstico. Guerreiro Ramos partilha com Polanyi a necessidade de uma abordagem substantiva. Ele confirma tanto a observação polanyiana da excepcionalidade histórica do domínio do mercado quanto a necessidade de fazer desaparecer as externalidades negativas que ele produz. Para ambos autores, a constatação é séria e a abordagem substantiva é necessária para considerar o retorno à sustentabilidade de nossos modelos econômicos. A pertinência do pensamento de Guerreiro Ramos, para além dessa constatação comum, é que ele prolonga a abordagem polanyiana no campo organizacional. 


\section{Convergência dos arcabouços conceituais de Polanyi e Guerreiro Ramos}

Assim, em fase com a intuição polanyiana de uma economia não baseada na escassez, Guerreiro Ramos corresponde com uma racionalidade substantiva que ele vai buscar em Weber. Essa racionalidade em valor lhe permite fazer a ligação com a economia substantiva de Polanyi e trazer a análise sobre a especificidade dos modos de tomada de decisão das organizações não mercantis. Com o seu conceito de paraeconomia, ele identifica três formas organizacionais fora do enclave do mercado. Trata-se da isonomia que favorece a igualdade em uma abordagem comunitária, a fenonomia que favorece a criação individual ou coletiva e a anomia que afeta indivíduos que foram marginalizados pelo mercado e que precisam de apoio e acompanhamento em organizações especificamente dedicadas a tal. Com essas três formas organizacionais, Guerreiro Ramos coloca as condições para a emancipação dos indivíduos do mercado e o caminho para a diversidade de uma sociedade multicêntrica.

O pluralismo que permite sua proposição teórica é particularmente relevante ao considerar a desmercadorização do que Polanyi chama de mercadorias fictícias: o trabalho, o dinheiro e a natureza. Enquanto, para Guerreiro Ramos, o mercado reduz o trabalho ao emprego, os enclaves da paraeconomia - isonomia e fenonomia - invertem a proposta. Eles substituem o emprego sofrido pelo trabalho escolhido e dão autonomia aos atores. Da mesma forma, a atividade econômica no seio das organizações da paraeconomia não tem por ambição de serem valorizadas e trocadas no mercado. Ela não supõe o uso de moeda convencional. Por serem animados e guiados por uma racionalidade substantiva, esses enclaves da paraeconomia protegem a natureza. No entanto, esses enclaves são frágeis. Por falta de meios, as fenonomias às vezes se refugiam no universo doméstico das famílias. As isonomias, por outro lado, são frequentemente levadas a confiar apenas no voluntariado. Portanto, a importância do papel do Estado e as políticas de redistribuição são importantes. Segundo Guerreiro Ramos, o Estado deve adotar uma visão pluralista em relação aos diferentes enclaves da paraeconomia. 
Não deve ceder à facilidade de julgá-los de acordo com os critérios do mercado. Esse é, sem dúvida, o maior perigo destacado por Guerreiro Ramos e uma de suas maiores contribuições teóricas.

Polanyi e Guerreiro Ramos compartilham a ideia de que o tempo e o espaço - como são apreendidos na lógica formal do mercado - não podem explicar toda a riqueza da criação humana. Ambos defendem uma abordagem diferente para essas questões. Polanyi mostra assim que o mercado pensa a troca no presente, sob uma forma que dissolve o social e condena o tempo longo da socialização. Para Guerreiro Ramos, o tempo não deve ser pensado de forma linear. As organizações paraeconômicas abrem-se, assim, para o tempo da convivialidade e da troca autêntica. Como tal, o tempo não pode ser reduzido a uma simples medida quantitativa.

\section{As perspectivas de pesquisa oferecidas por essa convergência}

Como acabamos de ver, os dois autores se complementam em termos de contribuições teóricas a fim de traçar os contornos de uma sociedade pluralista em que o mercado seria suficientemente controlado para ser potencialmente considerado como um enclave entre outros. Segundo Guerreiro Ramos, trata-se de proteger os enclaves fora do mercado da pressão desse último. Assim, cooperativas de sucesso podem se esvaziar caso seus cooperados mais dinâmicos sejam atraídos pelo financiamento do mercado. Eles podem ser tentados a se demitir ou a vender. Por estar muito perto do mercado, a organização autogestionária será "minada do interior pela ambição dos mais dinâmicos ou mais ávidos, e pela inércia dos outros". (COUTROT, 2002)

A questão central dos dois autores é se opor a um processo ideológico mortal de reduzir a economia ao mercado e a sociedade à sociedade de mercado. Ao mostrar o impacto desse reducionismo na psique humana, Polanyi e Guerreiro Ramos colocam luzes sobre a questão da violência no trabalho em organizações formais. A força dos dois autores se encontra na atualidade persistente de suas propostas conceituais. Não podemos deixar de fazer a ligação 
entre isonomias e associações ou organizações da economia solidária, e entre as fenonomias e os movimentos dos makers ${ }^{3}$ (LALLEMENT, 2015), os "profissionais amadores"4 (CALLON; LACOUSMES; BARTHES, 200I) ou as "empresas liberadas". ${ }^{5}$ (GILBERT; TEGLBORG; RAULET-CROSET, 20I7) Ao centro do seu paradigma, no eixo que liga as isonomias e as fenonomias, pode-se encontrar os atores que Stiegler (20I0) denomina como "a economia da contribuição", ou seja, os movimentos do software livre (FRANÇA FILHO; AGUIAR, 2OI4; AGUIAR, 20I6) e, mais amplamente, os comuns, como veremos mais adiante. Por fim, podemos ver uma extensão da reflexão sobre o tempo de Guerreiro Ramos nos trabalhos sobre slow manegement. ${ }^{6}$ (VITARI et al., 2013)

3 Estes movimentos reagrupam sujeitos que querem fabricar ou reparar, eles próprios, os produtos nos quais consomem. Podem ser grupos compartilhando, por exemplo, um fablab ou um simples atelier de costura ou de cozinha.

4 Estes são, por exemplo, os apaixonados por astronomia que realizam observações gratuitas com seus telescópios num contexto de ciência participativa.

5 As enterprises libérées são empresas que deixam seus assalariados organizarem o trabalham conforme bem entendem.

6 O slow management se construiu em oposição ao fast management, ou seja, distinguindo-se de uma gestão antes de tudo preocupada com os ganhos de produtividade e de performances cada vez mais elevados. Por sua vez, o slow management valoriza a autonomia, a participação das pessoas e a busca de sentido no trabalho. $O$ intuito é de se prevenir contra a desmotivação e o sofrimento ou adoecimento no trabalho. 